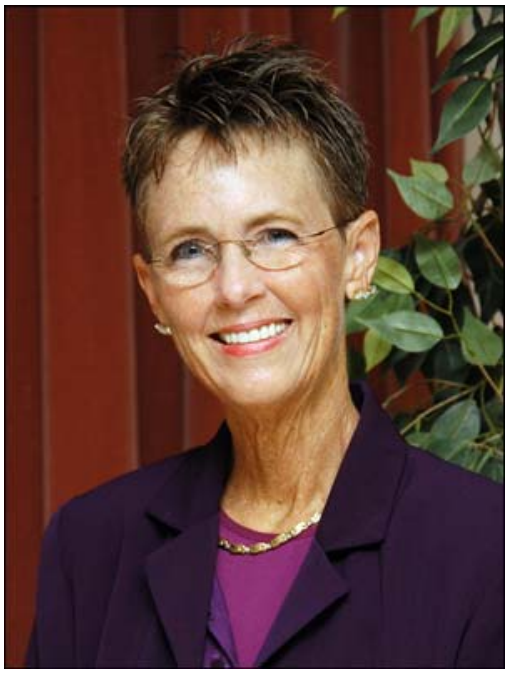

Pat Quigley, PhD, MPH, ARNP, FAAN

\title{
Prevention of fall-related injuries: A clinical research agenda 2009-2014
}

Decades of research have been conducted on the risk, prevention, and management of falls. Extensive research addresses the identified intrinsic and extrinsic fall risks and the importance of screening for these risks. The emphasis for patient safety interventions surrounding falls and injury prevention must be on patient-centered, multifactorial, individualized care plans that are population-based. Yet the link between risk assessment and the effectiveness of population-based interventions remains weak.

Early efforts focused on risk factors for prevention of falls in the elderly, largely ignoring interventions and also considering all fallers as one single group. Research then moved into fall screening and risk assessment, but these two processes were often intermingled, leading to confusion about linking risk to specific interventions. Still the focus was on fall prevention and the elderly, lumping all fallers into one single group. Next, research focused on interventions, but the focus was on fall prevention and the elderly, again lumping all fallers together.

A new agenda begins to question this focus on fall prevention and addresses fall protection and injury prevention, emphasizing therapeutic risk associated with activity and community participation. This new agenda also recognizes the need to segment high-risk patient populations to identify unique risks and tailor interventions (e.g., peripheral neuropathy, wheelchair fallers) using new three-dimensional techniques to assess gait and balance as well as other key risk factors. The new agenda also goes beyond fall screening and fall risk assessment, emphasizing the need to screen individuals, follow up with in-depth risk assessment protocols, and link interventions to specific modifiable risk factors.

As more evidence is available to clinicians, for translational research efforts are needed to develop clinical tools to make it easier for clinicians to provide evidence-based practice and to explore more effective and efficient strategies for implementing evidence-based programs across clinical settings and facilities. To advocate for evidence-based practice in fall prevention and fall protection, the Veterans Integrated Service Network (VISN) 8 Patient Safety Center of Inquiry held its second international call across professions and experts to articulate the state of the science, elucidate research priorities, and facilitate the translation of research into practice.

In April 2007, fall experts from the United States and Canada participated in a three-day national conference, "Transforming Fall Prevention Practices." After presenting state-of-the-art knowledge and practices in fall prevention, risk assessment, and interventions, they joined with invited research methodologists and expert clinicians over another half day for the research agendasetting session. Participants reached consensus on the research needed to advance both science and clinical practice. 
Priorities were grouped into three research domains:

- Clinical interventions.

- Biomechanics.

- Implementation/translation.

The criteria used for selecting research priorities were the-

- Need for consensus among all members.

- Feasibility of the research being conducted within 5 years.

- Presence of an existing program of research on which to build.

- Fit with the mission and vision of the Veterans Health Administration (VHA) in primary health promotion, patient safety, function, and independence.

This editorial focuses solely on clinical intervention. We examined the current state of the science relevant to clinical intervention research and developed a research agenda for studies that can be conducted as 5-year research programs likely to result in new discoveries, improved clinical practice, reduced variations in practice, and improved patient outcomes. Clinical intervention research is needed to test the effects of specific interventions related to special populations, medication prescribing, clinical units and staffing, and interdisciplinary approaches to fall prevention [1]. Both experimental and nonexperimental designs are appropriate in these studies. The members emphasized their need for using clinical trials and other prospective study designs rather than relying solely on retrospective epidemiological approaches and using fall-related injuries rather than falls as the ultimate outcome.

\section{STATE OF THE SCIENCE}

The consequences of falls include patient injury, discomfort, increased morbidity and mortality, treatment expenses, decreased quality of life, and professional liability. The most serious consequences of falls are hip fractures and intracranial bleeds. However, adverse outcomes go beyond the injuries sustained as a result of a fall [2]. Although an injury may not be the result of a fall, the faller may still harbor fear of a repeat fall and may consequently restrict another activity and lose confidence, mobility, and independence [3]. The evidence supports that multidisciplinary, multifactorial, health/environment risk-factor screening/intervention programs are effective for fall prevention in the community for both unselected populations of older people and for older people with a history of falling or known risk factors and in residential care facilities [4]. Individual interventions shown to be effective included muscle strengthening and balance retraining, individually prescribed by a trained health professional; home hazard assessment and modification for older individuals with a history of falling; withdrawal of psychotropic medications; cardiac pacing for fallers with cardio-inhibitory carotid sinus hypersensitivity; and a 15-week tai chi exercise intervention. Interventions with unknown effectiveness are group-delivered exercise interventions; individual lower-limb strength training; nutritional supplementation, including vitamin $\mathrm{D}$ with or without calcium; interventions using cognitive/ behavioral approaches; and others [4].

Evidence looking at specific interventions to decrease fall or injury risk is missing for certain high-risk populations such as those with Parkinson disease, stroke, knee osteoarthritis, or peripheral neuropathy [5].

Traditional fall prevention and fall management programs have not been fully effective in preventing falls in part because they have focused on environmental safety and physical restoration after a patient has fallen and sustained the negative consequences of the fall [6]. Traditional programs focus on physical skills and the interaction of the body with the environment but fail to implement interventions that apply protective wear that reduces the fall impact when a patient does fall. The evidence for interventions aimed at fall protection, such as hip protectors, is mixed [7]. While they have been shown effective for hip-fracture prevention in a number of cluster randomized trials in nursing home populations, that finding was not confirmed in individually randomized trials or in community-living older adults [8-9]. The limitations of those studies included a low adherence rate and issues related to durability of different 
brands of hip protectors and a need to replace them, suggesting the need for further research [10].

While a number of medication classes have shown association with increased risk for falling or injury [11-12], a paucity of evidence exists when it comes to medication management interventions, except for withdrawal of psychotropic medications, which commonly is not feasible because of the need for treatment of depression, anxiety, or psychosis in older people. No evidence exists on the availability of safer pharmacologic or nonpharmacologic alternatives [13].

Based on this review, our clinical research agenda priority addresses special populations, medications, clinical units and staffing, and an interdisciplinary approach to fall prevention.

\section{SPECIAL POPULATIONS (COCHRANE REVIEW-2006)}

Research is needed to develop and test effectiveness of multifactorial interventions for special vulnerable populations at risk for falls and for those at risk for serious injury that results in loss of function or death, such as persons who are newly disabled [14-16], cognitively impaired [16], wheelchairbound [17], diagnosed with osteoporosis [18-19], postoperative [20-21], using anticoagulation therapy [22-23], and over the age of 85 [24]. Also, research must examine factors that enhance positive outcomes in seriously injured older adults.

\section{MEDICATIONS}

Research is needed to (1) examine the role of medication reconciliation on falls and fall-related injuries, (2) compare the effects of different psychotropic medications from the same class gait and balance to determine the safest prescribing regime, (3) analyze alternatives to medications for promoting sleep, and (4) describe the biomechanical markers that best indicate that a patient is able to safely compensate and adapt to medication side effects.

\section{CLINICAL UNITS AND STAFFING}

Research is also needed to (1) examine nurse staffing models on the number and severity of falls and fall-related injuries [25], (2) analyze the effectiveness of 1:1 use of sitters or hourly nursing surveillance rounds on the number and severity of falls and fallrelated injuries among inpatients (acute care and longterm care settings) [26], (3) correlate key aspects of environmental design (e.g., space/layout, lighting, flooring, furniture arrangement, and proximity to toilet) on the number and severity of falls and fall-related injuries across settings of care, (4) test how the use of a designated "safe room" for high-risk patients affects the number and severity of falls and fall-related injuries, and (5) examine the effects of postfall safety huddles on repeat falls and injuries among inpatients.

\section{INTERDISCIPLINARY APPROACH TO FALL PREVENTION}

Lastly, research is needed to determine the appropriate use of fall risk screening tools in generating interdisciplinary interventions to prevent falls among inpatients and examine the best interdisciplinary intervention protocol (dose, frequency, and intensity) for treatment of known fallers or those identified at high risk for falls.

This research agenda specifically targets preventing falls and protecting from injury, building science, and changing practices related to reducing the severity of injury irrespective of the type of fall a patient experiences. Our research agenda for biomechanics and motor control also directs us to test approaches to reductions in falls and fall-related injuries only as it relates to clinical detection of deficits and interventions to reduce falls and fall-related injuries prior to ground impact. Biomechanical and motor control research is needed to test the effects of specific interventions related to concurrent tasks, compensatory reactions, falls in understudied settings or related to mobility device, changes across the life span, and outcomes measurement and translation. 
Our research agenda for implementation science continues to evolve. While we recognize that implementation science is rapidly evolving in general, we advocate the use of active rather than passive dissemination methods [27]. Examples of these methods include local opinion leaders to persuade colleagues and serve as role models for implementing best practices [28]; academic detailing, whereby experts deliver content and tools to providers to facilitate implementation [29]; matching implementation strategies and clinical tools to known barriers at patient, provider, and organizational levels [30]; incorporating current models of behavior change that address knowledge, attitudes, social influences, and self-efficacy of providers and patients (e.g., Theory of Planned Behavior [31]); and using current theories related to implementation to guide the research in this area (e.g., Diffusion of Innovation [32]). In general, these methods have been found to increase the rate of uptake of best practices and evidence-based interventions in clinical settings. The strength of evidence to support fall prevention and fall-injury prevention interventions varies by intervention and by setting. Effectiveness of patient safety interventions continues to unfold as the results of both clinical trials and cohort studies are published. In the work of innovation, evidence is emerging. Our assumption supports both building and advancing the level of evidence through quality improvement and research methods.

Should you be interested in our full report, please contact me at Patricia.Quigley@med.va.gov or visit http://www.visn8.med.va.gov/patientsafetycenter/fallsTeam/default.asp.

\section{REFERENCES}

1. Titler M, Dochterman J, Picone DM, Everett L, Xie XJ, Kanak M, Fei Q. Cost of hospital care for elderly at risk for falling. Nurs Econ. 2005;23(6):290-306. [PMID: 16459901]

2. Cho SH, Ketefian S, Barkauskas VH, Smith DG. The effects of nurse staffing on adverse events, morbidity, mortality, and medical costs. Nurs Res. 2003;
52(2):71-79. [PMID: 12657982]

DOI:10.1097/00006199-200303000-00003

3. Tennstedt S, Howland J, Lachman M, Peterson E, Kasten L, Jette A. A randomized, controlled trial of a group intervention to reduce fear of falling and associated activity restriction in older adults. J Gerontol B Psychol Sci Soc Sci. 1988;53(6):P384-92. [PMID: 9826971]

4. Gillespie LD, Gillespie WJ, Robertson MC, Lamb SE, Cumming RG, Rowe BH. Interventions for preventing falls in elderly people. Cochrane Database Syst Rev. 2003;4:CD000340. [PMID: 14583918]

5. Deane KH, Jones D, Playford ED, Ben-Shlomo Y, Clarke CE. Physiotherapy vs. placebo or no intervention in Parkinson's disease. Cochrane Database Syst Rev. 2001;3:CD002817. [PMID: 11687029]

6. Braun J, Capezuti L. The legal and medical aspects of physical restraints and bed siderails and their relationship to falls and fall-related injuries in nursing homes. DePaul J Health Care Law. 2000;4(1):1-72.

7. Gates S, Fisher JD, Cooke MW, Carter YH, Lamb SE. Multifactorial assessment and targeted intervention for preventing falls and injuries among older people in community and emergency care settings: Systematic review and meta-analysis. BMJ. 2008; 336(7636):130-33. [PMID: 18089892]

DOI:10.1136/bmj.39412.525243.BE

8. Parker MJ, Gillespie WJ, Gillespie LD. Effectiveness of hip protectors for preventing hip fractures in elderly people: Systematic review. BMJ. 2006; 332(7541):571-74. [PMID: 16513687]

DOI:10.1136/bmj.38753.375324.7C

9. Sawka AM, Boulos P, Beattie K, Thabane L, Papaioannou A, Gafni A, Cranney A, Zytaruk N, Hanley DA, Adachi JD. Do hip protectors decrease the risk of hip fracture in institutional and community-dwelling elderly? A systematic review and meta-analysis of randomized controlled trails. Osteoporos Int. 2005; 16(12):1461-74. [PMID: 15990949]

DOI:10.1007/s00198-005-1932-2

10. Kiel DP, Magaziner J, Zimmerman S, Ball L, Barton BA, Brown KM, Stone JP, Dewkett D, Birge SJ. Efficacy of a hip protector to prevent hip fracture in nursing home residents: The HIP PRO randomized controlled trial. JAMA. 2007;298(4):413-22.

[PMID: 17652295]

DOI:10.1001/jama.298.4.413 
11. Hartikainen S, Lönnroos E, Louhivuori K. Medications as a risk for falls: Critical systematic review. J Gerontol A Biol Sci Med. 2007;62(10):1172-81. [PMID: 17921433]

12. French DD, Campbell R, Spehar A, Cunningham F, Foulis P. Outpatient medications and hip fracture in the US: A national veterans study. Drugs Aging. 2005;22(10):877-85. [PMID: 16245960]

DOI:10.2165/00002512-200522100-00006

13. Montgomery P, Dennis J. Physical exercise for sleep problems in adults aged 60+. Cochrane Database Syst Rev. 2002;4:CD003404.

14. Mackintosh SF, Hill K, Dodd KJ, Goldie P, Culham E. Falls and injury prevention should be part of every stroke rehabilitation plan. Clin Rehabil. 2005;19(4): 441-51. [PMID: 15929514] DOI:10.1191/0269215505cr796oa

15. Dite W, Connor HJ, Curtis HC. Clinical identification of multiple fall risk early after unilateral transtibial amputation. Arch Phys Med Rehabil. 2007;88(1): 109-14. [PMID: 17207685] DOI:10.1016/j.apmr.2006.10.015

16. Sheridan PL, Hausdorff JM. The role of higher-level cognitive function in gait: Executive dysfunction contributes to fall risk in Alzheimer's disease. Dement Geriatr Cogn Disord. 2007;24(2):125-37.

[PMID: 17622760]

DOI:10.1159/000105126

17. Gavin-Dreschnack D, Nelson A, Fitzgerald S, Harrow J, Sanchez-Auguiano A, Ahmed S, Powell-Cope G. Wheelchair-related falls: Current evidence and directions for improved quality care. J Nurs Care Qual. 2005;20(2):119-27. [PMID: 15839290]

18. Sugioka Y, Koike T; World Health Organization. [Absolute risk for fracture and WHO guideline. Fall and fracture in elderly people: Risk factors and strategies for prevention.] Clin Calcium. 2007;17(7): 1059-65. Japanese. [PMID: 17607073]

19. Burgess E, Nanes M. Osteoporosis in men: Pathophysiology, evaluation, and therapy. Curr Opin Rheumatol. 2002;14(4):421-28. [PMID: 12118179] DOI:10.1097/00002281-200207000-00016

20. Stenvall M, Olofsson B, Lundström M, Englund U, Borssén B, Svensson, O, Nyberg L, Gustafson Y. A multidisciplinary, multifactorial intervention program reduces postoperative falls and injuries after femoral neck fracture. Osteoporos Int. 2007;18(2):167-75.
[PMID: 17061151]

DOI:10.1007/s00198-006-0226-7

21. Amador L, Loera J. Preventing postoperative falls in the older adult. J Am Coll Surg. 2007;204(3):447-53. [PMID: 17324780]

DOI:10.1016/j.jamcollsurg.2006.12.010

22. Bond AJ, Molnar FJ, Li M, Mackey M, Man-SonHing $M$. The risk of hemorrhagic complications in hospital in-patients who fall while receiving antithrombotic therapy. Thromb J. 2005;3(1):1.

[PMID: 15638939]

DOI:10.1186/1477-9560-3-1

23. Cappuzzo KA. Anticoagulation in elderly patients who fall frequently: A therapeutic dilemma. Consult Pharm. 2005;20(7):601-5. [PMID: 16548657]

24. Stevens JA. Falls among older adults-Risk factors and prevention strategies. NCOA Falls Free: Promoting a National Falls Prevention Action Plan. Research Review Papers. Washington (DC): The National Council on the Aging; 2005.

25. Cho SH, Ketefian S, Barkauska VH, Smith DG. The effects of nurse staffing on adverse events, morbidity, mortality and medical costs. Nurs Res. 2003;52(2): 71-79. [PMID: 12657982] DOI:10.1097/00006199-200303000-00003

26. Pappas SH. The cost of nurse-sensitive adverse events. J Nurs Adm. 2008;38(5):230-36. [PMID: 18469616] DOI:10.1097/01.NNA.0000312770.19481.ce

27. Thomson O'Brien MA, Freemantle N, Oxman AD, Wolf F, Davis DA, Herrin J. Continuing education meetings and workshops: Effects on professional practice and health care outcomes. Cochrane Database Syst Rev. 2001;2:CD003030. [PMID: 11406063]

28. Thomson O’Brien MA, Oxman AD, Haynes RB, Davis DA, Freemantle N, Harvey EL. Local opinion leaders: Effects on professional practice and health care outcomes. Cochrane Database Syst Rev. 2000; 2:CD000125. [PMID: 10796491]

29. Freemantle N, Nazereth I, Eccles M, Wood J, Haines A; Evidence-based OutReach trialists. A randomised controlled trial of the effect of educational outreach by community pharmacists on prescribing in UK general practice. Br J Gen Pract. 2002;52(477):290-95. [PMID: 11942445]

30. Hulscher ME, Wensing M, Van Der Weijden T, Grol R. Interventions to implement prevention in primary care. Cochrane Database Syst Rev. 2001;1:CD000362. [PMID: 11279688] 
31. Madden TS, Ellen PS, Ajzen I. A comparison of the theory of planned behavior and the theory of reasoned action. Pers Soc Psychol Bull. 1992;18(1):3-9. DOI:10.1177/0146167292181001

32. Rogers EM. Diffusion of innovations. 4th ed. New York (NY): Free Press; 1995.
Pat Quigley, PhD, MPH, ARNP, FAAN Associate Director, VISN 8 Patient Safety Center of Inquiry, James A. Haley VAMC, Tampa, FL

Email: Patricia.Quigley@med.va.gov

DOI:10.1682/JRRD.2009.07.0097 